\title{
Easy Ontology, quantification, and realism
}

\author{
Benjamin Marschall ${ }^{1}$
}

Received: 13 March 2019 / Accepted: 4 November 2019 / Published online: 18 November 2019 (c) The Author(s) 2019

\begin{abstract}
Amie Thomasson has defended a view called Easy Ontology, according to which most ontological questions can be answered straightforwardly using conceptual truths and empirical knowledge. Furthermore, she claims that this deflationary meta-ontology does not commit her to any form of anti-realism. In this paper I identify a problem with Thomasson's account of quantification, according to which everything we quantify over falls under a sortal. Thomasson's defence of the easiness of answering ontological questions relies on a certain thesis about the hierarchical order of sortals, but the case for the compatibility of Easy Ontology and realism suggests that this thesis is actually false.
\end{abstract}

Keywords Meta-Ontology · Easy Ontology · Amie Thomasson · Quantification · Realism · Anti-realism

\section{Introduction}

According to Amie Thomasson's easy approach to ontology, many ontological debates-like the one about the existence of composite objects-can be resolved easily. She thinks that there are analytic principles which, together with uncontroversial empirical knowledge, guarantee the existence of objects such as tables. There is thus no room for further metaphysical debates regarding the existence of composites (Thomasson 2007, 2009, 2015).

The claim that analytic principles or conceptual truths can be used to resolve certain ontological disputes is not new: Carnap, the Neo-Fregeans, and Stephen Schiffer have made similar proposals (Carnap 1956; Hale and Wright 2009; Schiffer 2003). One obvious worry about such accounts is that the price of answering ontological questions easily is to commit oneself to some form of anti-realism: for if we are realists, how could conceptual investigations suffice to find out what exists? One particularly

\footnotetext{
$凶$ Benjamin Marschall

bm515@cam.ac.uk

1 Darwin College, University of Cambridge, Cambridge, England
} 
compelling feature of Thomasson's account is that she defends the compatibility of Easy Ontology and realism at length (Thomasson 2007: Section 3.3, Thomasson 2015: Section 3.3). In this paper I will argue, however, that her account of quantification, according to which everything we quantify over falls under a sortal, makes it doubtful whether her defence of realism succeeds.

I will proceed as follows: first I introduce Easy Ontology and the question of realism. Then I reconstruct Thomasson's account of quantification, and illustrate how it differs from the mainstream view held by contemporary neo-Quinean ontologists. Furthermore, I show that her so-called categorical quantification view plays a crucial role in defending Easy Ontology against what I call the One More Thing-objection. Lastly I introduce two criteria for realism, and argue that while the first criterion poses no problem for Easy Ontology, meeting the second criterion seems to be incompatible with the response Thomasson gave to the One More Thing-objection. I conclude that this tension provides good reason to doubt whether Thomasson can actually make ontology easy in a realist manner.

\section{Easy Ontology and realism}

While Thomasson wants to deflate many ontological disputes, it will be convenient to focus on one particular case. The debate about composition is a good candidate, since there is plenty of skepticism regarding the fruitfulness of mereological disputes. ${ }^{1}$ The pertinent question is this: Are there composite objects, or merely simple particles? According to Thomasson's brand of meta-ontological deflationism, conceptual considerations combined with basic empirical knowledge suffice to establish the existence of composites. She argues that, taking one example, the following principle is a conceptual truth which is constitutive of the meaning of 'table':

(T) There is a table iff There are particles arranged table-wise. ${ }^{2,3}$

Given (T), it immediately follows that there are tables, and hence composite objects, since the existence of particles arranged table-wise is taken for granted in the debate.

This seems like an attractive view, but the fact that conceptual truths play a crucial role in answering ontological questions gives rise to the suspicion that we are dealing with a form of anti-realism, according to which the existence of (some) objects depends on the language or concepts we use. Already Carnap felt the need to distance himself from such a reading, here for the case of propositions:

\footnotetext{
1 Button (2016) calls mereology the "punchbag of contemporary metaphysics".

2 (T) actually combines two separate principles:

$\left(\mathrm{T}^{-}\right)$'Table' refers iff There are particles arranged table-wise.

(ER) $K$ s exist iff ' $K$ ' refers.
}

Strictly speaking only $\left(\mathrm{T}^{-}\right)$states the application condition for the term 'table', but to simplify matters I will also call $(\mathrm{T})$ an application condition.

3 For ease of exposition, I construe application conditions as biconditionals here, but in fact Thomasson only considers the right-to-left direction to be a conceptual truth. Our concept table presumably allows that there could be tables not made out of particles but out of gunk, an extended simple or mere stuff (Thomasson 2015: p. 106f). 
[...A ] statement of the existence of linguistic entities (e.g., expressions, classes of expressions, etc.) must contain a reference to a language. The fact that no such reference occurs in the existential statements here, shows that propositions are not linguistic entities. (Carnap 1956: p. 210f)

Similarly, although Schiffer calls propositions language-created, this does not mean that they literally didn't exist before we introduced that-clauses and other means to refer to them into our language. Instead it is merely supposed to flag that there is no way of knowing about such entities independently of language (Schiffer 1996: p. 159).

Despite these protestations, it is very common to read Carnap as an anti-realist (Biggs and Wilson 2016), and it has been argued that Schiffer's theory is not realist enough to account for inexpressible propositions (Hofweber 2016: p. 62f). It is thus important for Thomasson to tackle this crucial issue, and she does indeed provide a defence of realism, which I will critically discuss later on (Thomasson 2007: p. 65, 2015: pp. 148f, 155f).

Before we come to that we need to understand how Thomasson deals with existence claims in more detail though, and for that her account of quantification is central. In the following sections, I will therefore first provide a detailed reconstruction of her views of quantifiers, and then show that this account is essential in defending Easy Ontology against a popular objection. On the way there we will also encounter an assumption Thomasson makes about the hierarchical order of sortals, which — unexpectedly—will turn out to be important in the discussion of realism later on.

\section{Quantification}

\subsection{Bare and categorical quantification}

The core of Thomasson's proposal is a distinction between two kinds of quantification: bare quantification is quantification over everything whatsoever, whereas categorical quantification involves quantifying over specific kinds —or categories—of things. Given these characterisations, the crucial question is not whether both kinds of quantification are possible, which is relatively uncontroversial, but rather which of them is fundamental. The standard view is to adopt the priority of bare quantification:

\section{STANDARD VIEW}

Bare quantification à la $\exists x \Phi$ is fundamental, and when we want to quantify over things of a specific kind $K$, we can just restrict the fundamental quantifier to things of that kind: $\exists x(K x \& \Phi)$.

Thomasson, instead, reverses the order of explanation:

\section{Fundamental CATEGorical QUANTIFICATION}

Categorical quantification à la $[\exists x: K] \Phi$ is fundamental, and if we want bare quantification it needs to be built up using categorical quantifiers:

$\exists x \Phi$ iff $[\exists x: F] \Phi$ or $[\exists x: G] \Phi$ or $[\exists x: H] \Phi$ or ... 
This position, which I will call the fundamental categorical quantification view, is unfamiliar, and it has been doubted whether it really is a genuine alternative to the standard view (Schaffer 2009). Therefore we need to spend some time on understanding in which respect the position substantially differs from more mainstream views on quantification.

I symbolised the fundamental categorical quantifier as ' $[\exists x: F]$ '. This suggests a Geachian view, according to which the logical form of quantified statements contains a slot for sortals (Sider 2009: p. 419). However, Thomasson explicitly rejects this interpretation (as reported in Schaffer 2009: p. 149). This makes the following question pressing:

[...] [Thomasson's] considered view is conservative. She allows simple quantification. She would keep the simple syntax and the semantics of the existential quantifier exactly as per usual. So I ask, how could her view possibly have any radical implications for metaphysical disputes that turn on existential quantification, if the syntax and semantics of simple existential quantification are left intact? (Schaffer 2009: p. 149)

Thomasson suggests that the need to specify a domain is the clue to understanding her view (Thomasson 2009: p. 463f). But it is not so clear what she means by that. According to the orthodox view on which bare quantification is fundamental, categorical quantification over $F \mathrm{~s}$ is achieved by restricting the bare quantifier to $F$ s. Using a domain restrictor is plausibly a way of specifying a domain-and indeed Schaffer seems to read Thomasson as identifying domain specification with domain restriction (Schaffer 2009: p. 150f). However, if one thinks that categorical quantification is fundamental, specifying a domain should presumably not amount to restricting an allencompassing quantifier, since the priority thesis says precisely that such a quantifier depends on the categorical quantifiers — not the other way round.

On occasion Thomasson also talks about domains being 'generated' (Thomasson 2007: p. 124), and suggests that accepting new sortals can enlarge ones domain of quantification (Thomasson 2015: p. 72). This doesn't sound like domain restriction, but if taken at face-value seems to lead to a form of anti-realism according to which language somehow creates the objects we quantify over-which is a position Thomasson explicitly rejects (Thomasson 2007: pp. 63ff, 185ff). There is thus good reason to sympathise with Schaffer's complaint that it is not obvious what Thomasson's views on quantification really amount to.

\subsection{Assignments and the qua problem}

I will now show that these doubts about fundamental categorical quantification can be overcome. In order to properly understand Thomasson's account, the following is a key passage:

For the truth-evaluability of quantified claims ' $(\exists \mathrm{x}(\mathrm{Fx}))$ ' is parasitic on the truth-evaluability of substitution instances involving names (or other forms of singular reference) to pick out items in the domain, and thus relies on the truthevaluability of ' $\left(F n_{1}\right)$, ' ' $\left(\mathrm{Fn}_{2}\right)^{\prime} \ldots$ where ' $\mathrm{n}_{1},{ }^{\prime}$ ' ' $\mathrm{n}_{2}$,' and so on are names. But 
I have argued [...] that consideration of the qua problem gives us reason to hold that singular reference can only be disambiguated to the extent that names, demonstratives, and other singular terms are associated with a category (or categories) of entity to be referred to, where this involves presupposing certain frame-level application and coapplication conditions for the terms. (Thomasson 2007: p. 117)

The crucial clue here is that Thomasson takes the qua problem to be relevant for the semantics of quantification. The qua problem arises in connection with causal theories of reference: if we try to introduce a new name using, for instance, a pointing gesture, the pointing doesn't uniquely determine what the referent of the name is-it could be the table we pointed at, the colour of that table, or one of its surfaces. This underdetermination can be overcome by supplying some sortal, which specifies the kind of thing we intend to name. According to Thomasson, this shows that there can be no purely causal theory of reference, since descriptive components are needed to ensure determinate reference (Thomasson 2007: p. 38ff).

Now here's a tempting thought, which I think is implicit in the earlier quote:

$(\mathrm{ST} \rightarrow \mathrm{Q})$ If the qua problem arises for singular terms in natural language and needs to be resolved by invoking sortals, then we also cannot refer to objects in our semantic machinery for quantification without relying on sortals.

In order to see why that is plausible, consider this clause from the standard modeltheoretic semantics of quantification:

$$
\mathcal{M} \models \exists x \Phi \text { iff For some } \beta: \mathcal{M}, \beta \models \Phi(x)
$$

The role of the assignment function $\beta$ is to assign objects to variables. Consequently, $\Phi(x)$ is true relative to $\beta$ iff $\beta$ maps the variable $x$ to some object $o$ from the domain $D$ that satisfies $\Phi$. Now one might raise the following question:

Under what conditions can an assignment function $\beta$ map a variable $x$ to an object $o$ from $D$ ?

The standard answer is that there are no substantial conditions which constrain assignments. The assumption is that it is "possible to assign any object whatsoever to any variable whatsoever, whether or not that object can be described or otherwise individually selected" (Lavine 2000: p. 24).

Although standard, this view sits uneasily with what we learned from the qua problem. There the issue was that names, and other singular terms, don't determinately refer without the aid of sortals which disambiguate between multiple possible referents. Assigning objects to variables does not seem fundamentally different from using names to refer to objects, however: it is also a form of singular reference. Consequently, if a purely causal theory of reference is excluded by the qua problem, the idea that we can just arbitrarily assign any object to a variable - which amounts to saying that we can simply 'tag' objects without any further ado (Lavine 2000: p. 24) — seems to be in no better shape. ${ }^{4}$

\footnotetext{
4 This objection to the standard view of variable assignments can be strengthened by observing that the inference rules for the existential quantifier allow us to derive sentences involving constants, which function
} 
This consideration suggests that one should adopt a unified treatment: either demand sortals for both names and quantifiers, or neither. Since Thomasson requires sortals for names, she has to challenge the standard view of quantification as well. And given this we can now answer Schaffer's earlier question. While on the surface, Thomasson leaves the semantic clause

$$
\mathcal{M} \models \exists x \Phi \text { iff For some } \beta: \mathcal{M}, \beta \models \Phi(x)
$$

unchanged, she adds a substantial assumption about the domain:

\section{SORTAL CONSTRAINT}

Every element of the domain $D$ falls under a sortal.

The reason for this is that by their nature, the elements of the domain are the values of the assignment function, and we have just seen that assignments without sortals need to be rejected. This makes Thomasson's account distinctive, since on the orthodox understanding of quantification there is no such constraint on the domain.

This interpretation makes good sense of fundamental categorical quantification. On the opposing view according to which bare quantification is fundamental, reference is easy: we can effortlessly quantify over everything whatsoever, since every element in the domain can simply be 'tagged'. According to the priority of categorical quantification, however, the possibility of referring to objects is not just taken for granted, but needs to be secured with the help of sortals first. Unrestricted quantification needs to be build up step by step, and only covers things that fall under some sortal. This intuitive difference is reflected in the competing conceptions of whether there are any substantial constraints on variable assignments. ${ }^{5}$

\section{The One More Thing-objection}

\subsection{Existence and analyticity}

After this detailed reconstruction of what Thomasson's views on quantification are, I will now argue that accepting the Sortal Constraint is not just an optional feature that she could give up if needed. Rather, it plays an essential role in her defence of Easy Ontology against an objection that often arises against the claim that principles such as

(T) There is a table iff There are particles arranged table-wise

\footnotetext{
Footnote 4 continued

as (temporary) names. If we take the qua problem for singular terms seriously we should therefore also require sortals for quantified claims, since the fomer are derivable from the latter.

5 One might worry that Thomasson relies on a substitutional reading of the quantifiers in the quote cited above, whereas I talked about objectual quantification. This distinction is inessential here, however. As has been repeatedly argued, plausible versions of substitutional quantification are equivalent to objectual quantification in that both require the possibility of referring to arbitrary objects somehow (Lavine 2000; Button and Walsh 2018: Chapter 1) - and whether this reference is achieved by variables or constants doesn't affect Thomasson's case for the Sortal Constraint.
} 
are analytic (Field 1989; Boolos 1998; Merricks 2000; Schaffer 2009; Bennett 2009; MacBride 2017).

The complaint is as follows: $(\mathrm{T})$ cannot be a conceptual truth, since it makes a substantial demand on reality. It is only true if, in addition to the particles, there is also an object composed by them, namely the table (Bennett 2009: p. 56). I will call this the One More Thing-objection (OMT), since critics are upset by the fact that (T) is supposed to entail the existence of one more object than the truth of its right-hand side seems to require.

If one is convinced by the OMT-objection one should maintain that, if there is a conceptual truth in the vicinity of (T) at all, it has to be

(T*) There is a table iff There are particles arranged table-wise and they compose an object.

And this would be a problem for proponents of Easy Ontology, since ( $\left.\mathrm{T}^{*}\right)$ doesn't enable us to easily derive the existence of tables. After all, whether particles arranged table-wise compose an object or not is just the contentious issue we were trying to settle.

Thomasson grants that if sense could be made of the idea that there needs to be an additional object or thing, hard ontology can be revived:

[...] all hopes for using the special composition question in arguments against ordinary objects rely on the idea that we can make sense of this [...] use of 'thing'. (Thomasson 2007: p. 136)

Her strategy, however, is to argue that there is no way of understanding 'thing' and 'object' such that the worry above can be raised. And this leads us to quantification, since serious metaphysicians usually adopt the following definition of 'object':

$a$ is an object if and only if $\exists x(x=a)$ (Schaffer 2009: p. 152)

Given this, one can rephrase $\left(\mathrm{T}^{*}\right)$ :

( $\left.\mathrm{T}^{* *}\right)$ There is a table iff There are particles arranged table-wise and $\exists x$ (the particles compose $x$ ).

And since Thomasson doesn't want to throw quantification and identity over board, we need some explanation of what is wrong with ( $\left.\mathrm{T}^{* *}\right)$ in order to stick with $(\mathrm{T})$. Luckily the Sortal Constraint introduced earlier, together with some other principles Thomasson accepts, provides just such an explanation.

\subsection{Easy Ontology defended}

In order to defend Easy Ontology against the OMT-objection, Thomasson needs to show that it is a mistake to replace her principle

(T) There is a table iff There are particles arranged table-wise with $\left(\mathrm{T}^{*}\right)$, or more specifically with the quantificational version: 
(T**) There is a table iff There are particles arranged table-wise and $\exists x$ (the particles compose $x$ ).

As I will now show, fundamental categorical quantification as described above enables us to give an argument against ( $\left.\mathrm{T}^{* *}\right)$. In order for it to succeed, however, we need to rely on two background assumptions which Thomasson outlines in her writings. The first is a constraint on what can legitimately count as an application condition:

\section{NON- CIRCULARITY}

Application conditions must not have the form: "Ks exist iff .... and Ks exist ..." (see Thomasson 2015: p. 99, 2017: p. 139f)

The rationale behind this is straightforward. Application conditions are supposed to informatively state the conditions under which the term ' $\mathrm{K}$ ' refers, and thus to explain when Ks exist. They cannot fulfil this job if they are circular though, because then we would need some other way to establish whether Ks exist. Thus while biconditionals such as "Tables exist if and only if some particles compose a table" are true, they are not informative enough to deserve the title of an application condition. ${ }^{6}$

The second assumption concerns the relation of different sortals:

\section{HIERARCHY OF SORTALS}

If $F$ is a sortal (e. g. mammal) and $G$ is some more specific sortal falling under $F$ (e. g. tiger), then the application conditions for $F$ will depend on the application conditions of the more specific sortal $G$ (and the other sortals falling under $F$ ) (see Thomasson 2007: p. 41f).

This is a substantial principle, which - among other things - is required for Thomasson's argument that the so-called covering use of 'object' is of no help to the hard ontologist to work (Thomasson 2009: p. 460). Thomasson says little in direct support of it, but let us take it on board for now, as we will revisit its plausibility at a later stage.

We are now in a position to construct an argument against ( $\left.\mathrm{T}^{* *}\right)$ which follows a line of reasoning Thomasson uses on a similar occasion (Thomasson 2009: p. 459f). First, note that according to the account on the table, ' $\exists x$ (the particles compose $x$ )' can only be true if there is some sortal $S$ which enables the variable $x$ to refer.

Secondly, consider the question: which sortal can fulfil this job? Presumably tiger and fridge won't do. If the table-wise arranged particles compose anything, it will be a table. So we either need the sortal table itself, or some more general sortal, like piece of furniture or material object.

If the sortal table is required to ensure the truth of ' $\exists x$ (the particles compose $x$ )', the Non-Circularity condition is violated though. Remember that if $\left(\mathrm{T}^{* *}\right)$ replaces (T), the former is not merely supposed to be a true biconditional. Instead ( $\left.\mathrm{T}^{* *}\right)$ is supposed to spell out the application conditions for 'table', so it needs to explain when 'table' is correctly applied, and hence when tables exist. But since according to the fundamental categorical quantification view, the truth of the right-hand side of ( $\left.\mathrm{T}^{* *}\right)$ already depends on the sortal table, and hence on the existence of tables, this

\footnotetext{
6 See Brenner (2018) for a recent objection to the Non-Circularity principle though.
} 
explanatory function cannot be fulfilled. Thomasson is thus in a position to reject the move from $(\mathrm{T})$ to $\left(\mathrm{T}^{* *}\right)$, since $(\mathrm{T})$ doesn't suffer from this problematic circularity.

One might think that using a more general sortal like material object solves this problem. Against this, Thomasson can rely on the Hierarchy of Sortals assumption, according to which the application conditions of material object are fulfilled only if those of some more specific sortal are fulfilled as well. In consequence, the circularity problem reappears, just in a more indirect manner. Whether material object can be used to refer to some object ultimately depends - in case the relevant object is a table-on whether the sortal table applies. At this point, we can then refer back to the previous argument.

My interpretation of categorical quantification thus delivers the desired result. Since on this construal the alternative proposals are circular, Thomasson is well-placed to insist that $(\mathrm{T})$, not $\left(\mathrm{T}^{*}\right)$ or $\left(\mathrm{T}^{* *}\right)$, is the constitutive principle about tables. Ontology remains easy.

\section{Realism reconsidered}

\subsection{Two tests for realism}

We now have an intelligible account of what fundamental categorical quantification amounts to, and also saw how the Sortal Constraint helps to answer the OMT-objection. In this section we will come back to the question of realism by introducing two tests for realism: the counterfactual test and the Hamlet test. ${ }^{7}$ We will see that while the counterfactual test is no hurdle for Easy Ontology, this test is very weak in that even self-consciously anti-realist views can pass it. Then I will argue that passing the Hamlet test is more challenging, and ultimately threatens to commit Thomasson to a view of sortals which is incompatible with her response to the OMT-objection.

The counterfactual test for anti-realism is straightforward. For a view to be realist, it needs to make counterfactuals such as the following true:

(C) If there had been no minds in the universe, there still could have been tables.

It is clearly correct that being able to account for the truth of $(\mathrm{C})$ is a necessary condition for a view to be realist. And as Thomasson convincingly argues, her Easy Ontology has no problem here. Since the application conditions for (T) don't mention the existence of minds as a condition for the existence of tables, there is no reason why she would have to deny that (C) is true (Thomasson 2007: p. 65f).

While passing the counterfactual test is a necessary condition for realism, it is arguably not sufficient. For consider the following card-carrying form of anti-realism about composition: Pearce's Mereological Idealism (MI), according to which "it is when a plurality is unified in thought under a concept that a unified whole comes to exist" (Pearce 2017: p. 200). On this view, the existence of composite objects is mind-dependent in a way Thomasson rejects, and one would thus expect that MI fails the counterfactual test. As Pearce points out, however, even given MI the standard

\footnotetext{
7 The latter test is inspired by Korman (2019: Section 5).
} 
semantics for counterfactuals actually makes (C) true. This is because we evaluate possible cases using our concepts, according to which tables are unified wholes, even though in the possible world under consideration there are no concept-users around (Pearce 2017: p. 207). ${ }^{8}$

The upshot of this is that the counterfactual test is quite weak, as few positions actually fail to pass it. An analogous point has already been made by Hilary Putnam, who comments on the question of realism as follows:

Human minds did not create the stars or the mountains, but this 'flat' remark is hardly enough to settle the philosophical question of realism versus antirealism.

(Putnam 1990: p. 30)

More specifically, I think we should add another necessary condition for realism: passing the Hamlet test.

Whereas the counterfactual test is about whether, once we have the means to talk about certain entities, we can truly say that they would exist even if we weren't around, the Hamlet test concerns, as it were, whether we can truly say that there are more things in heaven and earth than are dreamt of in our current language and theories. Less metaphorically: in order to pass the Hamlet test, a theory must allow for the possibility that there might be objects which do not fall under any sortal we have in our language. For it is hard to see how the claim that necessarily everything there is can be described using the conceptual resources we actually have could be motivated apart from some form of idealism - and a realist should hence avoid this commitment. Let us thus consider how the Sortal Constraint fares on that front.

\subsection{Concepts and predicates}

It will be useful to draw a distinction between two kinds of things one could mean by 'sortal'. On the one hand, there are sortal predicates such as 'is a tiger', which are linguistic entities. On the other hand, there are sortal concepts, which are expressed by sortal predicates - these might be mental or abstract, but their precise nature doesn't matter for our purposes here. And crucially, while it seems clearly true that our language doesn't contain all possible sortal predicates, this does not entail that we don't have all sortal concepts at our disposal. After all, it would be unreasonable to assume that we can use a concept only if we have an atomic predicate that corresponds to it in our language (Lowe 2007: p. 515). ${ }^{9}$

In light of this, consider again the Sortal Constraint:

\section{SORTAL CONSTRAINT}

Every element of the domain $D$ falls under a sortal.

This is ambiguous between requiring sortal predicates or sortal concepts. On the predicate-reading the Hamlet test poses a problem for Thomasson, for consider the following claim (adapted from Korman 2019: p. 241):

\footnotetext{
8 Thanks to an anonymous referee for pointing me towards Pearce's view.

9 Thanks to an anonymous referee for alerting me of the need to distinguish between sortal predicates and concepts.
} 
(H) There are objects which do not fall under any sortal.

If we read $(\mathrm{H})$ as referring to sortal predicates, the truth-conditions for it are as follows: $(\mathrm{H})$ is true iff there is an object in the domain such that no sortal predicate in our language applies to it. But this condition can only obtain if we can quantify over objects which don't fall under a sortal predicate-which is precisely what the predicatereading of the Sortal Constraint denies.

The situation is different, however, when we read the Sortal Constraint as demanding that objects fall under sortal concepts. For then $(\mathrm{H})$ can be true-provided we still read it as applying to sortal predicates - if we have sortal concepts to which no atomic predicate of our language corresponds. And since the intuition that $(\mathrm{H})$ is true seems to depend on the fact that our language doesn't contain all possible sortal predicates, this strategy solves the problem, provided that Thomasson is in a position to make sense of the concept-reading of the Sortal Constraint. ${ }^{10}$

The turn to sortal concepts introduces complications for Thomasson though. While it is plausible that not all sortal concepts need to correspond to sortal predicates we actually have in our language, their independence should not be exaggerated either. Thomasson needs to hold that for any sortal concept it is in principle possible to add a predicate corresponding to it to our language (Thomasson 2019: p. 259), so on her view there can be no sortals that are in principle inexpressible.

To see why this is so, we can start from Thomasson's remark that a sortal is essentially a way to "divide things up" (Thomasson 2007: p. 124). For any sortal concept $S$, there must thus be some condition that determines which objects fall under it and which don't. But this condition just is what Thomasson calls an application condition, and so it will be possible to introduce a sortal predicate $P$ which expresses $S$ by associating $P$ with the appropriate application conditions. ${ }^{11}$ There is thus no room for in principle inexpressible sortal concepts, unless we throw the whole idea of application conditions — which is obviously essential to Thomasson's project—over board.

So far it seems as if the Hamlet test is no serious problem for Easy Ontology. A more detailed look at how the introduction of sortals is supposed to work, however, will reveal a hidden tension with Thomasson's answer to the OMT-objection.

\subsection{Hierarchy of sortals reconsidered}

The tension within Thomasson's account is best illustrated by an example: the discovery of a new animal species X. The proposal under discussion has it that after the discovery a new sortal predicate for Xs is introduced into our language. Since the

\footnotetext{
10 Some might even find the requirement that everything we can quantify over must fall under a sortal concept objectionable, since they think that genuine realism requires the possibility that there are objects which are not conceptualisable at all, such as Johnston's Enigmas (Johnston 1993: p. 96). I think it is correct that Thomasson will not be able to account for that eventuality, but for the purposes of this paper I will not consider whether this is a reasonable condition for realism or not. For discussion see the dispute between Hofweber and Schiffer about how to make sense of inexpressible properties and propositions (Hofweber 2016; Schiffer 2016).

11 Note that Thomasson doesn't assume that application conditions must be statable, so the introduction of $P$ doesn't have to take the form of a definition of $P$ in other terms, but may merely consist in $P$ being used in certain ways (Thomasson 2015: p. 91).
} 
sortal concept for Xs had been available all along, however, it was already possible to quantify over Xs before the introduction of this predicate.

The interesting question now is how the introduction of the new sortal predicate works. Earlier I only mentioned the need to add application conditions for X, but that cannot be all there is to it, for $\mathrm{X}$ will be related to other sortals in various ways. In particular, X will fall under the sortal animal, and also one of the more specific sortals such as mammal, insect, etc. In reply to an objection by Evnine (2016), Thomasson stresses that this coordination of different sortals is achieved by other analytic principles which are not the application conditions strictly speaking:

[...] proper sortal terms (as I have often insisted) must come with application conditions and coapplication conditions, and may also come with other constitutive rules of use, for example, relating their use to that of other terms. It is the presence of these other rules in constituting what it is our term means, even when it is used in the existence question, that can ensure that the things referred to (if any) have other features. (Thomasson 2015: p. 225)

This raises the following question: when adding the new sortal $\mathrm{X}$ to our language, is it a matter of mere choice whether we add constitutive rules that classify $\mathrm{X}$ as a mammal as opposed to an insect or a fish? Presumably not. The plausible thing to say is that high-level sortals put certain constraints on low-level sortals, such that every new sortal that comes with certain properties must fall under one high-level sortal rather than another. On this picture, the meaning of low-level sortals is thus partly determined by high-level sortals.

This story comes with a cost though. Remember that when discussing the OMTobjection, we saw that Thomasson accepts the following principle:

\section{HIERARCHY OF SORTALS}

If $F$ is a sortal (e. g. mammal) and $G$ is some more specific sortal falling under $F$ (e. g. tiger), then the application conditions for $F$ will depend on the application conditions of the more specific sortal $G$ (and the other sortals falling under $F$ ) (see Thomasson 2007: p. 41f).

This was crucial in order to argue that any attempt to state application conditions in such a way that the existence of tables becomes doubtful - for instance by requiring that particles arranged table-wise need to compose a material object-becomes circular. So for the argument against the OMT-objection to work, low-level sortals must determine the meaning of high-level sortals.

The tension that Thomasson's account faces is now obvious. Rebutting the OMTobjection and passing the Hamlet test suggest two ways of thinking about the relation between sortals that pull in opposite directions. The process of introducing new sortals suggests that high-level sortals constrain what low-level sortals can fall under them. But since this entails that high-level sortals must have application conditions which are not fully determined by more specific sortals, it becomes unclear why there could not be cases in which we can, for instance, meaningfully ask whether some things compose a material object independently of whether they compose a table, a chair, and so on. 
One might object that this is not a serious issue, for even though there are some conditions associated with the sortal material object that are not determined by lowlevel sortals, no one could dispute that ordinary objects such as tables fulfil these conditions - so hard ontology cannot be revived. Fair enough, but note that Thomasson actually endorses a form of mereological universalism, according to which every collection of particles composes an object (Thomasson 2007: p. 183ff, see also Button 2016: Section 3), and is hence committed to objects such as in-cars and trout-turkeys. Since it is by no means obvious that the ordinary meaning of material object is such that these unusual objects fall under it, it seems that hard ontology can be revived at least for these cases.

Could Thomasson respond by sticking with the Hierarchy of Sortals principle and modifying her reply to Evnine? I don't think this is an option, for the thought that high-level sortals constrain the meaning of low-level sortals appears to be an essential feature of our use of sortals. Taking the Hierarchy of Sortal principle seriously, on the other hand, would have the strange consequence that every introduction of a new sortal into our language changes the meaning of many of the high-level sortals - and this is a description of the situation which seems completely unmotivated. We therefore have weighty reasons to retain Thomasson's reply to Evnine and reject the Hierarchy of Sortals principle as implausible instead. And while this helps Thomasson to pass the Hamlet test, it undermines her response to the OMT-objection-and thus the easiness of Easy Ontology is in danger. ${ }^{12}$

\section{Conclusion}

In this paper I did three things. First, I presented a reconstruction of Thomasson's views on quantification, in which I showed that what makes her account non-standard is the Sortal Constraint. Secondly, I pointed out that the Sortal Constraint plays an important role in her defence of Easy Ontology, since it enables her to rebut the One More Thingobjection. Thirdly, I argued that the Hierarchy of Sortals principle Thomasson relies on in this rebuttal is questionable, since a plausible account of how Easy Ontology can pass the Hamlet test for realism is incompatible with this principle. This is of course no final refutation of Thomasson's attempt to make ontology easy in a realist manner. But she either needs a detailed defence of the Hierarchy of Sortal principle, or a new way to respond to the OMT-objection—and neither task looks easy.

\footnotetext{
12 Thomasson has recently suggested that she can avoid the complications I discussed because we have the sortal concept S-object at our disposal, under which all concrete objects fall (Thomasson 2019: p. 258f). I think this response raises more questions than it answers though, for at least three reasons: (i) Thomasson originally introduces S-object as a sortal applying to "medium-sized lumps of stuff well bonded together but independently mobile from surrounding stuff" (Thomasson 2009: p. 458). But this is insufficiently general, for not all concrete objects are medium-sized and well bonded. (ii) Later, Thomasson suggests that S-objects are 'Spelke objects', i.e. objects that are perceived as unified (Thomasson 2015: p. 109f, 2019: p. 258). This still doesn't cover all concrete objects, and introduces the additional problem that the sense of object here seems to be purely phenomenological, and not that of a physical object in space and time (see Brenner 2018: section 4). (iii) Even if the notion of an S-object could do the job Thomasson envisages, more would need to be said about how it relates to other sortals, and how it can be reconciled with the Hierarchy of Sortals principle.
} 
Acknowledgements I thank Tim Button, Amie Thomasson, the GOMS-group (Annie Bosse, Lucy McDonald, Nathan Hawkins), and two anonymous referees for helpful feedback on earlier versions of this paper. I also thank the audiences of the 7th International Philosophy Graduate Conference at CEU Budapest and the 2018 Joint Session at the University of Oxford, where I had the opportunity to present parts of this work. My research was supported by a studentship from the Arts and Humanities Research Council and a scholarship from the Cambridge Trust.

Open Access This article is distributed under the terms of the Creative Commons Attribution 4.0 International License (http://creativecommons.org/licenses/by/4.0/), which permits unrestricted use, distribution, and reproduction in any medium, provided you give appropriate credit to the original author(s) and the source, provide a link to the Creative Commons license, and indicate if changes were made.

\section{References}

Bennett, K. (2009). Composition, colocation, and metaontology. In D. J. Chalmers, D. Manley, \& R. Wasserman (Eds.), Metametaphysics: New essays on the foundations of ontology (pp. 38-76). Oxford: Oxford University Press.

Biggs, S., \& Wilson, J. M. (2016). Carnap, the necessary a priori, and metaphysical anti-realism. In S. Blatti \& S. Lapointe (Eds.), Ontology after Carnap (pp. 81-104). Oxford: Oxford University Press.

Boolos, G. (1998). Is Hume's principle analytic? In R. Jeffrey (Ed.), Logic, logic, and logic (pp. 301-314). Cambridge: Harvard University Press.

Brenner, A. (2018). Easy ontology, application conditions and infinite regress. Analysis, 78(4), 605-614. https://doi.org/10.1093/analys/any029.

Button, T. (2016). Deflationary metaphysics and ordinary language. Synthese. https://doi.org/10.1007/ s11229-016-1212-z

Button, T., \& Walsh, S. (2018). Philosophy and model theory. Oxford: Oxford University Press.

Carnap, R. (1956). Empiricism, semantics, and ontology. In Meaning and necessity (pp. 205-221). Chicago: University of Chicago Press.

Evnine, S. (2016). Much ado about something-from-nothing; or, problems for ontological minimalism. In S. Blatti \& S. Lapointe (Eds.), Ontology after Carnap (pp. 145-163). Oxford: Oxford University Press.

Field, H. (1989). Platonism for cheap? Crispin Wright on Frege's context principle. In Realism, mathematics and modality (pp. 147-170). Oxford: Blackwell.

Hale, B., \& Wright, C. (2009). The metaontology of abstraction. In D. J. Chalmers, D. Manley, \& R. Wasserman (Eds.), Metametaphysics: New essays on the foundations of ontology (pp. 178-212). Oxford: Oxford University Press.

Hofweber, T. (2016). From Remnants to Things, and back again. In G. Ostertag (Ed.), Meanings and other things: Themes from the work of Stephen Schiffer (pp. 54-72). Oxford: Oxford University Press.

Johnston, M. (1993). Objectivity refigured: Pragmatism without verificationism. In J. Haldane \& C. Wright (Eds.), Reality, representation, and projection (pp. 85-130). Oxford: Oxford University Press.

Korman, D.Z. (2019). Easy ontology without deflationary metaontology. Philosophy and Phenomenological Research, 99(1), 236-243. https://doi.org/10.1111/phpr.12617.

Lavine, S. (2000). Quantification and ontology. Synthese, 124(1-2), 1-43.

Lowe, E. J. (2007). Sortals and the individuation of objects. Mind and Language, 22(5), 514-533. https:// doi.org/10.1111/j.1468-0017.2007.00318.x.

MacBride, F. (2017). Neo-Fregean meta-ontology: Just don't ask too many questions. In P. Ebert \& M. Rossberg (Eds.), Abstractionism: Essays in philosophy of mathematics. Oxford: Oxford University Press.

Merricks, T. (2000). No statues. Australasian Journal of Philosophy, 78(1), 47-52. https://doi.org/10.1080/ 00048400012349341.

Pearce, K. L. (2017). Mereological idealism. In T. Goldschmidt \& K. L. Pearce (Eds.), Idealism: New essays in metaphysics. Oxford: Oxford University Press.

Putnam, H. (1990). A defense of internal realism. In J. F. Conant (Ed.), Realism with a human face (pp. 30-42). Cambridge: Harvard University Press.

Schaffer, J. (2009). The deflationary metaontology of Thomasson's Ordinary Objects. Philosophical Books, $50(3), 142-157$. 
Schiffer, S. (1996). Language-created language-independent entities. Philosophical Topics, 24(1), $149-167$.

Schiffer, S. (2016). Pleonastic entities: Responses to Amie Thomasson, Thomas Hofweber, Ian Rumfitt, and Michael Smith. In G. Ostertag (Ed.), Meanings and other things: Themes from the work of Stephen Schiffer (pp. 387-425). Oxford: Oxford University Press.

Schiffer, S. (2003). The things we mean. Oxford: Oxford University Press.

Sider, T. (2009). Ontological realism. In D. J. Chalmers, D. Manley, \& R. Wasserman (Eds.), Metametaphysics: New essays on the foundations of ontology. Oxford: Oxford University Press.

Thomasson, A. L. (2007). Ordinary objects. Oxford: Oxford University Press.

Thomasson, A. L. (2009). Answerable and unanswerable questions. In D. J. Chalmers, D. Manley, \& R. Wasserman (Eds.), Metametaphysics: New essays on the foundations of ontology (pp. 444-471). Oxford: Oxford University Press.

Thomasson, A. L. (2015). Ontology made easy. Oxford: Oxford University Press.

Thomasson, A. L. (2017). Carnap and the prospects for Easy Ontology. In S. Blatti \& S. Lapointe (Eds.), Ontology after Carnap (pp. 122-144). Oxford: Oxford University Press.

Thomasson, A. L. (2019). Replies to comments on. Ontology Made Easy. Philosophy and Phenomenological Research, 99(1), 251-264. https://doi.org/10.1111/phpr.12619.

Publisher's Note Springer Nature remains neutral with regard to jurisdictional claims in published maps and institutional affiliations. 